\title{
DE LA MALDAD EUROPEA Y LA SOBERANÍA POPULAR
}

\begin{abstract}
C ace algunos años, tuve ocasión de participar en la polémica que suscitó el libro de Elías Díaz De la maldad estatal y la soberanía popular ${ }^{1}$. Los problemas que entonces se discutieron en el marco del Estado, deben ser planteados hoy día también a nivel europeo. En este trabajo se pretende proseguir aquélla discusión, suscitando el interrogante acerca de quién detenta el poder constituyente -entendido como faceta de la soberanía-, en el proceso de construcción europea.
\end{abstract}

\section{Soberanía y poder constituyente}

\section{Concepto de soberanía}

Entenderemos aquí por «soberanía» una potestad que, desde el punto de vista jurídico, aparece como una facultad incondicionada de decisión reflexiva.

Carácter incondicionado de la decisión soberana.

Ya Hegel reconoció la existencia de un componente decisionista en el ejercicio de todas las funciones estatales, idea que, luego, sería recogida por Schmitt. Ese componente decisionista es descrito por Hegel como un momento de autodeterminación absoluta de la voluntad $^{2}$. Es

${ }^{1}$ Díaz, Elías, De la maldad estatal y la soberanía popular, Madrid, Debate. 1984.

${ }^{2}$ Cfr. $§ 275$ de su Filosofía del Derecho. 
decir, se trata de aquel momento en que quien resuelve elige entre unas alternativas que pueden aparecer igualmente fundadas, eliminando así la incertidumbre ${ }^{3}$. Este componente decisionista o de autodeterminación absoluta de la voluntad puede descubrirse por ejemplo en la resolución de un caso concreto en base a una ley, en la decisión acerca de la constitucionalidad de una ley o en las decisiones gubernamentales.

Ahora bien, no todos los órganos que «deciden» en este sentido son soberanos, pues pueden estar sujetos a controles ulteriores. En realidad, sólo son soberanos los órganos que «deciden» y no tienen que responder ante ningún otro órgano de su decisión. Éste es el sentido que Bodin atribuía al carácter «absoluto» de la soberanía: el soberano no tiene que responder jurídicamente de sus decisiones ante ninguna otra instancia, externa o interna ${ }^{4}$. La capacidad de violar el derecho sería una característica de los órganos soberanos que, para Bodin, constituiría un rasgo derivado del carácter absoluto de la soberanía ${ }^{5}$. El carácter incondicionado de la decisión soberana pone de manifiesto, pues, que el poder del Estado es, en última instancia, jurídicamente incontrolable, incluso en el caso del Estado de Derecho.

Carácter reflexivo de la soberanía: la soberanía como competencia de competencias

El carácter reflexivo de esa facultad de decisión incondicionada que es la soberanía consiste en que la soberanía puede entenderse como una competencia de competencias. Una referencia a este rasgo de la soberanía se encuentra ya en una afirmación colateral del Contrato social de Rousseau. Rousseau pone de manifiesto que no

${ }^{3}$ Cfr. $§ 279$ de su Filosofía del Derecho. El momento de la decisión se encuentra más allá de las razones. En el dominio de las razones se pueden contraponer unas a otras. La decisión rompe o quiebra la ponderación entre unas razones y otras con un «yo quiero». (Véase al respecto Bourgeois, Bernard: «El príncipe hegeliano» (1979), ahora en AA.VV.: Estudios sobre la Filosofía del Derecho de Hegel, Madrid, Centro de Estudios Constitucionales, 1989, págs. 289-317, págs. 310-11).

${ }^{4}$ El príncipe soberano está obligado a dar cuenta sólo a Dios (Véase Bodin, Jean: Los Seis Libros de la República, (Sel. trad. y estudio preliminar de Pedro Bravo Sala), Madrid, Tecnos, 1992, 2. ${ }^{\text {a }}$ ed., pág. 49 y pág. 60. Véase también Franklin, Julian H.: «Introduction» a Bodin, Jean: On Sovereignty, Cambridge Univ. Press, 1992, págs. IX-XXVI, págs. XXII y XXIII.

${ }^{5}$ El príncipe absoluto puede derogar, cambiar, establecer excepciones o violar las leyes, porque éstas dependen exclusivamente de su voluntad (Véase Bodin, Jean: Los Seis Libros de la República, págs. 52-3 y 63). Por el contrario, para Schmitt, la capacidad de violar el derecho constituiría el rasgo esencial de la soberanía (Véase Schmitt, Carl: Teología Política, en ID.: Escritos Políticos, trad. cast. de Francisco Javier Conde, págs. 33-108, pág. 40). 
existe una delimitación clara y objetiva entre lo que sea público y lo que sea privado. Es decir, no puede establecerse una distinción neta entre lo que sea materia propia de decisión del individuo y lo que sea materia de decisión de la voluntad general. De ello se desprende, desde el punto de vista de Rousseau, que el soberano no sólo decide incondicionadamente, sino que puede decidir acerca de qué decide ${ }^{6}$.

\section{El poder constituyente}

Históricamente el surgimiento del concepto de soberanía aparece ligado al proceso de formación de las monarquías absolutas. Cuando, en una segunda fase, la soberanía se atribuye al pueblo, éste aparece como el titular último de la misma y el Estado como la instancia que ejerce la soberanía por delegación ${ }^{7}$. Este cambio del sujeto de la soberanía conlleva, pues, un cambio de su ejercicio.

El primer momento en que se elabora este cambio desde un punto de vista jurídico se encuentra en los trabajos de los primeros constitucionalistas franceses y, en particular, de Sieyés. Estos autores identificaron y delimitaron el poder constituyente como faceta de la soberanía. El poder constituyente reúne las características del poder soberano pues es incondicionado (el titular del poder constituyente no responde jurídicamente ante ninguna otra instancia) y reflexivo (el poder constituyente decide acerca de qué cuestiones debe tratar la constitución). Para los primeros constitucionalistas franceses, el poder constituyente es el núcleo del poder soberano, en la medida en que identifican la creación de la Constitución con el contrato social.

La titularidad de esta faceta de la soberanía la atribuyeron directamente al pueblo. Por ello, el poder constituyente tenía carácter intransferible: el pueblo no puede renunciar a la titularidad de este poder ${ }^{8}$. El poder constituyente puede, sí, ser delegado en representantes elegidos por el pueblo, pero dichos representantes deben haber sido dotados de un mandato específico para dar la Constitución 9 .

${ }^{6}$ «[...] lo que cada uno enajena por el pacto social es sólo la parte de su poder, de sus bienes, de su libertad cuyo uso importa a la comunidad; pero hay que convenir también que únicamente el soberano puede juzgar acerca de esta importancia» (Rousseau, J. J., Du Contrat Social, Paris, Garnier, 1975, pág. 253).

${ }^{7}$ Capella, J. R., «Una visita al concepto de soberanía», en ID.: Los ciudadanos siervos, Madrid, Trotta, 1993, págs. 117-134, pág. 123.

${ }^{8}$ Sieyés, E, Fundamentos del Estado (1794), en Escritos y Discursos de la Revolución, trad. de Ramón Maíz, Madrid, Centro de Estudios Constitucionales, 1990, págs. 234-244, pág. 241.

${ }^{9}$ Sieyés, Proemio a la Constitución (1789), en Escritos y Discursos de la Revolución, págs. 83-108, pág. 90. 
Precisamente, el problema que se plantea en torno a la titularidad del poder constituyente en el proceso de construcción europea es si ha tenido lugar una transferencia de dicho poder constituyente desde los pueblos a los parlamentos de los Estados miembros o, incluso, a los órganos europeos.

\section{El tratado de Maastricht y el poder constituyente europeo}

Desde un punto de vista material, el poder constituyente consiste en la facultad de adoptar las decisiones políticas fundamentales. En particular, las decisiones acerca de la titularidad del ejercicio de las facultades soberanas, acerca de la forma de Estado y acerca de los derechos fundamentales.

Como he tenido ocasión de argumentar en otro trabajo ${ }^{10}$, en el caso de la construcción europea se han adoptado o modificado decisiones políticas fundamentales de manera informal; o de manera formal, pero sin participación del titular del poder constituyente. En particular, la violación de los principios del Estado de Derecho por parte del «orden constitucional» europeo no sólo representa un déficit democrático de las instituciones europeas, sino que tiene un impacto en los ordenamientos constitucionales que altera determinados elementos de los mismos (supeditación del poder ejecutivo al legislativo, supeditación del poder judicial al legislativo, etc. $)^{11}$.

Además de las mutaciones que han tenido lugar como consecuencia del impacto del funcionamiento institucional europeo, se han verificado también modificaciones informales de las constituciones de los Estados miembros como consecuencia de la atribución de potestades soberanas a los órganos europeos por medio de las cláusulas de escape ${ }^{12}$.

\section{El Tratado de la Unión Europea y la reforma constitucional alemana}

El problema de la mutación y de la pérdida de contenido de las constituciones estatales en favor de los organismos europeos se ha agudizado con la firma en Maastricht del Tratado de la Unión Europea.

${ }^{10}$ Estévez Araujo, José A., «El problema de la unidad europea y de los Estados nacionales», en Mientras tanto, 57, 1994. págs. 35-48.

${ }^{11}$ Véase también Muñoz Machado, Santiago, La Unión Europea y las mutaciones del Estado, Madrid, Alianza, 1993, esp. págs. 42-50.

${ }^{12}$ Por ejemplo el art. 93 de la Constitución española, en virtud del cual por medio de ley orgánica pueden ratificarse tratados internacionales que impliquen transferencias de competencias derivadas de la Constitución. 
Por el Tratado de la Unión las partes contratantes constituyen una «Unión Europea»Art. A, párr. 1 TUE) que tiene los siguientes objetivos: crear un espacio económico y social sin fronteras interiores; crear una unión económica y monetaria, con una moneda común a largo plazo; afirmar su identidad internacional con una política exterior y de seguridad común; crear una ciudadanía europea; una cooperación estrecha en el ámbito de la justicia y de los asuntos de interior; mantener y desarrollar el acervo comunitario (Art. B TUE).

La Unión se configura sobre tres «pilares» que son las tres Comunidades (CEE -ahora CE-; CECA y EURATOM), la cooperación en el ámbito de la política exterior y de seguridad común y la cooperación en el ámbito de la justicia y los asuntos de interior (Art. A, párr. 3 TUE). La Unión hereda el «organigrama» de las Comunidades europeas (Consejo, Comisión y Parlamento) con el añadido del Consejo Europeo. El art. F párr. 3 del TUE prevé que la Unión pueda dotarse de los medios necesarios para alcanzar sus objetivos y llevar a cabo sus políticas. Por último el TUE transforma la Comunidad Económica Europea en la Comunidad Europea (Art. G), dotándola de más competencias y funciones.

La Unión Económica y Monetaria (UEM) constituye el aspecto central de los acuerdos de Maastricht. Esta Unión supone una política económica común de los Estados que se basa en una serie de principios entre los que destaca la defensa de una economía «de mercado y libre competencia» (art. 102 A del tratado CE). El objetivo «primordial» de la política económica común es «mantener la estabilidad de los precios» (art. 3 A del Tratado CE). La culminación de la Unión Económica y Monetaria vendrá dada por la creación de una moneda única, un Banco Central Europeo y de un Sistema Europeo de Bancos Centrales.

La actitud de los Estados europeos acerca del impacto que los acuerdos de Maastricht tienen sobre sus respectivos ordenamientos constitucionales ha sido diversa. En el caso español se minimizó este impacto y se consideró que la cláusula de escape era suficiente para cubrir las transferencias que se deberían realizar en virtud del TUE. En cambio, en Francia y Alemania se consideró necesario hacer una reforma de la Constitución que permitiera integrar el TUE en el ordenamiento constitucional.

En concreto, como consecuencia de la reforma constitucional alemana, el nuevo art. 23.1 de la Ley Fundamental señala que con el fin de contribuir a la creación de una Europa unida, la República Federal Alemana participa en el desarrollo de la Unión Europea. Este artículo vincula la Unión Europea al principio del Estado social y democrático de Derecho, al principio federal, al principio de subsidiariedad y a una protección de los derechos fundamentales similar a 
la existente en la RFA. En este artículo se reconoce, asimismo, la facultad de atribuir por Ley, con el acuerdo del Bundesrat, el ejercicio de derechos de soberanía con este fin. Se ha considerado, pues, necesario reconocer una facultad específica de atribuir facultades soberanas para contribuir al desarrollo de la Unión Europea, diferente de la habilitación genérica para atribuir por Ley simple el ejercicio de derechos de soberanía a instituciones interestatales contenida en el art. 24. 1.

Por su parte, en el art. 23.3 se obliga al Gobierno a consultar al Bundestag respecto al proceso de normación europea y a tener en cuenta sus pronunciamientos en las negociaciones. Por último, el art. 88 permite atribuir las competencias del Bundesbank al Banco Central Europeo, el cual debe ser independiente y perseguir como objetivo primordial la estabilidad de los precios ${ }^{13}$.

\section{Recursos ante el Tribunal Constitucional Alemán contra la ratificación del Tratado de Maastricht}

Contra esta ley de reforma de la Ley Fundamental de 21 de diciembre de 1992 y contra la Ley de 28 de diciembre de 1992 de ratificación del Tratado de la Unión Europea se interpusieron dos recursos ante el Tribunal Constitucional Alemán. Estos recursos seguían básicamente dos líneas de argumentación: una referida al déficit democrático de los órganos europeos, la otra referida a la transferencia de soberanía a los órganos europeos vía Parlamento $^{14}$.

El déficit democrático de la Comunidad -y, por tanto, de la Unión- deriva de que el verdadero legislador es el Consejo -es decir, los gobiernos-, teniendo el Parlamento un papel esencialmente consultivo. En los recursos se considera que este déficit vulnera el art. 38.1 de la Ley Fundamental ${ }^{15}$. En este artículo se reconoce el derecho a la participación política. $\mathrm{Y}$ en los recursos, se argumenta que el contenido esencial de este derecho consiste en la participación en la elección del verdadero órgano legislativo. Este contenido esencial resulta vulnerado porque los ciudadanos alemanes no eligen

${ }^{13}$ Sobre la reforma constitucional alemana v. Bacigalupo, Mariano: «El impacto del Tratado de la Unión Europea en la reforma constitucional alemana de 21 de diciembre de 1992», en Revista Española de Derecho Constitucional, 39, 1993, págs. 161-92.

${ }^{14}$ La sentencia que resolvió estos recursos ha sido publicada en $N J W, 1993$, 47, págs. 3.047-3.058. Los argumentos de los recurrentes se entresacan de dicha publicación.

${ }^{15}$ Art. 38. 1: «Los diputados del Parlamento Federal Alemán son elegidos por sufragio universal, directo, libre, igual y secreto $[\ldots] »$. 
directamente al órgano legislativo europeo, sino que el legislador europeo tiene únicamente la legitimación democrática indirecta que corresponde a los gobiernos de los Estados miembros.

En los recursos se considera también vulnerado el principio democrático, componente fundamental e intangible del ordenamiento constitucional alemán, de acuerdo con el art. 79.3 de la Ley Fundamental.

Por lo que se refiere a la transferencia de la soberanía a la Unión, los recurrentes señalan que, antes de la firma del Tratado, el $80 \%$ de la legislación económica y el $50 \%$ de la totalidad de las leyes alemanas venían determinadas por el derecho comunitario. El volumen e incidencia de la normativa europea resultaría aún mayor como consecuencia del Tratado de la Unión, por lo que se sustraerían más materias a la decisión del Bundestag. Este hecho se valora como una ampliación de los poderes y competencias de la Unión a todas las materias determinantes para la configuración de un Estado. Al asumir la facultad de transferir competencias soberanas en este grado, el parlamento alemán estaría pretendiendo ejercer potestades propias del poder constituyente. Por consiguiente, las leyes deberían haber sido sometidas a la aprobación del pueblo como titular del poder constituyente.

En los recursos se considera incluso que el art. F párr. 3 del Tratado atribuye a la Unión una «competencia de competencias» ${ }^{16}$, lo cual supondría un vaciamiento del contenido de las atribuciones del Bundestag. Pues en virtud de este artículo, la Unión Europea podría acrecentar motu propio sus competencias sustrayéndoselas a los Estados. De ser correcta esta interpretación, se habría llevado a cabo una transferencia del poder constituyente no a los parlamentos estatales, sino a los órganos europeos.

\section{Sentencia del Tribunal Constitucional Alemán de 12-10-93}

La sentencia del Tribunal Constitucional Alemán no admitió uno de los recursos y desestimó el otro en base a una serie de argumentos que podemos clasificar en dos apartados: los referidos al problema de la soberanía y los referidos al problema de la democracia.

\section{El problema de la soberanía}

En la sentencia se subraya el hecho de que el Tratado de la Unión no constituye un Estado europeo. El Tratado configura una Unión

${ }^{16}$ Se trata del artículo ya mencionado en el que se señala que la Unión se dotará de los medios necesarios para alcanzar sus objetivos y llevar acabo sus políticas. 
Europea de Estados. Se refiere a la participación de Alemania en instancias supranacionales y no a su integración en un Estado europeo. El Tratado reconoce, además, la identidad nacional de los Estados miembros ${ }^{17}$.

Por otro lado, la Sentencia señala que las competencias decisorias del Bundestag no quedan vaciadas de contenido: el art. F apdo. 3 del Tratado no atribuye a la Unión Europea una competencia de competencias. De acuerdo con el Tribunal Constitucional Alemán, este artículo no autoriza a la Unión Europea a dotarse motu propio de medios de actuación. Simplemente expresa la voluntad programática de los Estados de dotar a la Unión de los medios suficientes según las exigencias y de acuerdo con los procedimientos establecidos en cada caso ${ }^{18}$.

Así pues, de acuerdo con el Tribunal, la firma del Tratado de la Unión no supone una pérdida de la sustancia estatal de Alemania ni una atribución del poder constituyente a los órganos europeos.

\section{El problema de la democracia}

En lo que se refiere al problema de la democracia, el Tribunal interpreta el artículo 38.1 de la Ley Fundamental en el sentido de que se reconoce a todo ciudadano alemán con derecho al voto el derecho subjetivo a participar en la elección de los diputados del Bundestag. Este artículo, así interpretado, impondría al nuevo art. 23 de la Ley Fundamental el límite de que la participación ciudadana en el ejercicio de los poderes soberanos no debe vaciarse de contenido por medio de transferencias de competencias propias del Bundestag a las instancias europeas ${ }^{19}$.

A la inversa, el Tribunal Constitucional identifica el contenido esencial del principio democrático con dos exigencias: la exigencia de que el ejercicio de las competencias estatales pueda «atribuirse» (zurückführen) al pueblo, y la exigencia de que pueda hacerse responsable a quien ejerce esas competencias ante el pueblo ${ }^{20}$.

De acuerdo con el Tribunal, el derecho de participación y el principio democrático no habrían sido vulnerados puesto que, como ya se ha señalado, las competencias del Bundestag no habrían resultado vaciadas de contenido.

El Tribunal Constitucional alemán considera suficiente el grado

\footnotetext{
${ }^{17}$ Véase $N J W, 1993,47$, pág. 3.050.

${ }^{18}$ Véase $N J W, 1993,47$, pág. 3.053.

${ }^{19}$ Véase $N J W, 1993,47$, pág. 3.048.

${ }^{20}$ Véase $N J W, 1993,47$, pág. 3.050.
} 
de legitimación de la Unión Europea. Esta legitimación se obtendría, por un lado, a través del propio Parlamento europeo. Pero, sobre todo, se obtendría a través del «acoplamiento» (Rückkoppelung) de la actuación europea con los parlamentos de los Estados miembros ${ }^{21}$. Y la reforma constitucional alemana garantizaría la necesaria influencia del Bundestag en las decisiones europeas ${ }^{22}$.

No obstante, el alto Tribunal señala que si se diera una preponderancia de competencias y facultades en manos de la Unión, sería insuficiente la legitimación a través de los parlamentos de los Estados miembros. Parece, pues, que desde el punto de vista del Tribunal con Maastricht no se ha concentrado un volumen de competencias en manos de los órganos europeos lo suficientemente grande como para cuestionar la legitimación democrática de la Unión.

Se añade, por último, en la Sentencia -de una forma totalmente dogmática- que resulta más aceptable en el caso de la Unión europea que el poder de dictar normas legislativas esté en manos de órganos ejecutivos de lo que resultaría en el caso de los Estados miembros ${ }^{23}$.

\section{Necesidad de un proceso constituyente europeo}

El Tribunal presenta, pues, una visión más desleída que los recurrentes de las exigencias democráticas de la Constitución alemana. No se trata de que los ciudadanos pueda participar en la elección del verdadero órgano legislativo. Únicamente se exige que de alguna manera, directa o indirecta, se pueda «atribuir» a los ciudadanos el ejercicio de facultades estatales como la legislación y que se pueda considerar de algún modo responsables a quienes ejercen dichas funciones frente a ellos.

Por lo que respecta al problema de si el volumen de competencias que pueden asumir los órganos europeos en virtud del TUE es o no excesivo para el grado de legitimación actual, habría que señalar que el Tribunal Constitucional parece minimizar la importancia y contenido de las transferencias que se pueden realizar en virtud del Tratado. Sin embargo, hay que tener en cuenta que la parte esencial del Tratado se refiere a la Unión Económica y Monetaria, que debe culminar en la emisión de una moneda única. La emisión de esta moneda no dependerá de decisiones políticas, sino de un comité de expertos que actuará de acuerdo con determinados automatismos.

\footnotetext{
${ }^{21}$ Véase $N J W, 1993,47$, pág. 3.051.

${ }^{22}$ Véase $N J W, 1993,47$, págs. 3.052-53.

${ }^{23}$ Véase $N J W, 1993,47$, pág. 3.052.
} 
Todos los gobiernos perderán la posibilidad de emitir moneda. Perderán la posibilidad de revisar la paridad de su moneda con otras divisas y verán estrechadas sus facultades en materia de política fiscal ${ }^{24}$. Estas atribuciones parecen, pues, lo suficientemente importantes como para considerar que afectan al núcleo esencial del ejercicio de la soberanía estatal.

A diferencia de lo que sostiene el Tribunal Constitucional Alemán, aquí se defiende la tesis de que facultar a los parlamentos europeos a transferir competencias soberanas de esta índole a los órganos europeos constituye una traslación ilegítima del poder constituyente. De acuerdo con la tradición de pensamiento democrático, el titular del poder constituyente es el pueblo y este poder no es transferible, sino únicamente delegable por medio de un mandato específico para dar la constitución. Por ello, se defiende la exigencia de que se abra un proceso constituyente europeo de carácter explícito en el que los ciudadanos europeos puedan debatir y decidir acerca de sus instituciones y sus derechos.

\section{El pueblo europeo y el bien común}

\section{El sujeto titular del poder constituyente}

El problema que plantea la exigencia de la apertura de un proceso constituyente europeo es el del sujeto titular del poder constituyente: ¿son los diferentes pueblos europeos o el «pueblo europeo»? La inclinación por la segunda de las opciones se fundamenta en la necesidad de que exista un sujeto político europeo que sea capaz de abordar los problemas sociales y económicos que hoy día tienen, inevitablemente, una dimensión supraestatal.

De acuerdo con una de las concepciones más optimistas acerca de la posibilidad de configurar una ciudadanía europea -la de Habermas-, esta ciudadanía no exigiría una base nacional, sino únicamente una cultura política común. Pero, según el propio Habermas, esta ciudadanía precisaría ser activada por un «trasfondo de motivos favorables» de un ciudadano «orientado al bien común» ${ }^{25}$. Y es ahí donde reside el principal problema en el caso europeo, pues como ya señaló Rousseau para que sea posible la voluntad general es necesario que los intereses particulares tengan algo en común: «sustraed [de las voluntades particulares] lo más y

\footnotetext{
${ }^{24}$ Montes, Pedro, La integración europea, Madrid, Trotta, 1993, pág. 149.

${ }^{25}$ Habermas, J., «Ciudadanía e identidad nacional. Consideraciones sobre el futuro europeo», en Debats, 39, 1992, págs. 12-18, págs. 14-16.
} 
lo menos que se destruyen entre ellos. Queda, por suma de las diferencias, la voluntad general $»^{26}$. Los intereses no deben ser, pues, absolutamente antagónicos como ocurriría -dice Rousseau- «si algunos tuvieran mucho y otros nada» ${ }^{27}$. O -podríamos decir nosotros- como ocurriría si el proceso que se generara hiciera más ricos a los que más tuvieran y más pobres a los que menos. Pero ése es precisamente el tipo de proceso que ha puesto en marcha la construcción europea a partir del Acta Única y de la creación de un mercado único.

\section{El mercado único europeo}

El objetivo del Acta Única fue la creación de un mercado único europeo de carácter homogéneo. Este objetivo exigía la eliminación de las barreras técnicas, físicas y fiscales al comercio entre los Estados. Era necesario, por tanto, entre otras cosas, llevar a cabo una homogeneización de la legislación interna de los Estados en lo relativo a las exigencias técnicas a que eran sometidos determinados productos (electrodomésticos, material de transporte, aparatos electrónicos, etc.). De este modo, se podrían fabricar los mismos productos para todo el mercado europeo ${ }^{28}$.

La puesta en práctica del Acta Única dio lugar a una internacionalización de la economía de los Estados europeos, que se puso de manifiesto en un gran incremento del comercio comunitario y en el aumento de las fusiones y absorciones de empresas ${ }^{29}$. Supuso, asimismo, una revisión del papel del Estado en la economía y, en particular, de los mecanismos de intervención, regulación y control del mercado.

La implantación de un mercado único se realizó partiendo de realidades económicas muy diversas. Los puntos de partida de los países eran muy distintos en lo relativo a niveles de renta y riqueza, niveles salariales, dotaciones de infraestructuras, etc. También eran diversos los puntos de partida de las distintas regiones europeas en esos mismos aspectos. El proceso que se puso en marcha con la implantación del mercado único tendió a agudizar esas diferencias y a generar una dinámica de competencia entre Estados,

${ }^{26}$ Rousseau, J. J., Du Contrat Social, pág. 252.

${ }^{27}$ Rousseau, J. J., Du Contrat Social, pág. 249 nota 1.

${ }^{28}$ Montes, Pedro, La integración europea, pág. 121.

${ }^{29}$ Montes, Pedro, La integración europea, pág. 121 y Commission des Communautés Européennes: Croissance, Competitivité, Emploi. Les défis et les pistes pour entrer dans le XXI siècle (Livre Blanc), publicado en el suplemento 6/93 del Bulletin des Communautées Européennes, pág, 72 . 
regiones, empresas y trabajadores para obtener mejores posiciones ${ }^{30}$.

\section{En particular, el caso español}

Esta agudización de las diferencias se ve claro por medio del análisis de las consecuencias que ha tenido para España la integración en la CEE. El aparato productivo español se ha mostrado incapaz para hacer frente a la competencia exterior y ello ha generado en la industria y también en la agricultura un proceso de desmantelamiento, reconversión y destrucción de puestos de trabajo. Esta incapacidad ha dado lugar, también, a un enorme déficit en la balanza de pagos. Ha tenido lugar, asimismo, una importante penetración de capital extranjero que o bien ha realizado operaciones especulativas, o bien se ha centrado en la adquisición de empresas españolas con el fin de eliminar la competencia y adueñarse de las redes de distribución ${ }^{31}$.

El Gobierno ha seguido una política de tipos de interés altos para atraer capitales extranjeros, lo que ha dado lugar a una sobre-cotización de la peseta, a un aumento de los costes financieros de las empresas y a un incremento de la deuda pública. Durante el quinquenio 1985-90 tuvo lugar una redistribución de la renta en favor de los beneficios, se extendió el empleo precario, disminuyó el gasto público destinado a servicios sociales y se impuso una política fiscal regresiva ${ }^{32}$.

Los derechos de los trabajadores han experimentado un retroceso como consecuencia de la desregulación del mercado de trabajo, que disminuye la capacidad negociadora del conjunto de los trabajadores en general y de los trabajadores precarios en particular. El concepto de «Estado del Bienestar» ha experimentado una revisión de modo que «la aspiración de un Estado del Bienestar cuanto más desarrollado mejor debía dejar paso a un Estado del bienestar básico que cubriera las necesidades sociales al nivel mínimo imprescindible para garantizar la estabilidad social $»^{33}$.

Por último «mientras el resto de los países asumía la complejidad y las dificultades de la integración europea, el Gobierno socialista aceleraba el cumplimiento de las condiciones de Maastricht estrangulando la economía, fomentando las desigualdades sociales, desmantelando

${ }^{30}$ Cfr. Albarracín, Jesús y Montes, Pedro: «El sueño liberal engendra monstruos. La Europa de Maastricht y la convergencia española» en AA. VV.: La izquierda y Europa, Madrid, IU-La Catarata, 1922, págs. 50-108, págs. 60, 70 y 80-1.

${ }^{31}$ Montes, Pedro, La integración europea, págs. 161-64.

${ }^{32}$ Montes, Pedro, La integración europea, págs. 162-63.

${ }^{33}$ Montes, Pedro, La integración europea, pág. 182. 
el esquelético Estado del Bienestar y destruyendo los derechos y conquistas de los trabajadores. El sueño de Europa bien valía estos sacrificios $\iota^{34}$.

\section{La situación presente}

\section{El Sistema Monetario Europeo y la Moneda Única}

El objetivo de implantar una moneda única estableciendo, primero, un sistema de cambios fijo entre las monedas europeas ha mostrado ya ser inviable. Un tipo de cambios fijo genera desequilibrios en las balanzas de pagos de los países menos competitivos, lo que delata que la relación de intercambio entre los países afectados y los demás países no es de equilibrio. El déficit de la balanza de pagos mina la confianza en la moneda y genera movimientos especulativos. Estas operaciones de acoso no pueden ser contrarrestadas por los mecanismos del Sistema Monetario Europeo (intervención de los Bancos Centrales), dado el volumen de capital que interviene en las mismas ${ }^{35}$.

La opción por la devaluación de la moneda para mejorar la competitividad significa que habrá que entregar una parte mayor de la producción para obtener a cambio los mismos productos (es decir, un deterioro de la relación de intercambio). Pero, de ese modo, se puede conseguir vender productos que no encontrarían compradores a los precios actuales. Sin embargo, en el momento en que se implantara una moneda única se perdería la capacidad de modificar el tipo de cambio. Se mantendrían y aumentarían las diferencias entre países ricos y pobres: las zonas menos competitivas tenderían a empobrecerse, «cada vez tendrán menos bienes que producir $\mathrm{y}$, por consiguiente, cada vez menos que comprar» ${ }^{36}$.

\section{La globalización de la economía}

Uno de los elementos en los que más pone el acento el «Libro Blanco» para caracterizar la situación actual es el de la globalización

${ }^{34}$ Montes, Pedro, La integración europea, pág. 185.

${ }^{35}$ Montes, Pedro, La integración europea, págs. 136-39.

${ }^{36}$ Montes, Pedro, La integración europea, pág. 150. Sin embargo a autores como Tamames el problema más enjundioso que parece plantearles el objetivo de la moneda única es cómo poder utilizar en un billete todos los idiomas de los países de la Comunidad (V. Tamames, Ramón, La Unión Europea, Madrid, Alianza, 1994. pág. 316). 
de la economía. En la actualidad están desapareciendo los contornos económicos clásicos, Resulta imposible delimitar la industria y su entorno geográfico en porciones distinguibles: las empresas comunitarias producen en territorios de terceros mercados y los competidores de la Comunidad instalan sus filiales en el territorio de ésta. Se llevan a cabo numerosos acuerdos estratégicos entre las grandes empresas multinacionales y se verifica, asimismo, un aumento de la vaguedad de los contornos de los propios sectores industriales ${ }^{37}$.

En esta situación de globalización de la economía ha cambiado la estructura del comercio mundial. En la actualidad, tiene un papel central el intercambio de productos semielaborados entre empresas. El desarrollo de las redes informáticas permite una cooperación más flexible entre las empresas. Y para los exportadores es cada vez más importante la reglamentación interna de cada país en materia de fiscalidad, seguridad y protección del consumidor que los derechos de importación ${ }^{38}$.

\section{El problema del paro}

De acuerdo con el Libro Blanco, el problema del paro en Europa es producto de un crecimiento débil del empleo en relación a la producción. En el período 1970-92, Estados Unidos ha experimentado un crecimiento económico del $70 \%$ y un crecimiento del empleo del 49\%. Europa ha experimentado en el mismo período un crecimiento económico del $81 \%$ y un crecimiento del empleo de sólo el 9\% (España ha experimentado un crecimiento económico del $103 \%$ y un decrecimiento del empleo del 0'3 \% $)^{39}$.

De acuerdo con este informe, en Europa se corre el peligro de generar una sociedad dual como consecuencia de que los beneficios del crecimiento de la producción económica han sido fundamentalmente para aquellos trabajadores que han conservado su empleo. Se ha generado una disparidad entre trabajadores fijos a tiempo completo, por un lado, y trabajadores temporales o a tiempo parcial, por otro. Asimismo, se constata una dificultad de acceso al trabajo de determinados sectores de la población (jóvenes, mujeres, trabajadores no cualificados $)^{40}$. Este análisis de una sociedad dual de parados y trabajadores precarios por un lado y trabajadores fijos a tiempo completo, por otro, parece olvidar, sin embargo,

${ }^{37}$ Livre Blanc, pág. 63.

${ }^{38}$ Livre Blanc, pág. 109.

${ }^{39}$ Livre Blanc, págs. 130-31.

${ }^{40}$ Livre Blanc, págs. 131, 133-34 y 140. 
el problema de la distribución de la renta entre salarios y beneficios empresariales. La creación y explotación del saber como fuente de la riqueza de las naciones

El Libro Blanco subraya en repetidas ocasiones la consideración de que en la actualidad, la creación y explotación del saber es la fuente más importante de la riqueza de las naciones. Este saber se traduce en formación, en capacidad organizativa de las empresas, en investigación y desarrollo y en la aplicación industrial de los frutos de la investigación ${ }^{41}$. Las pequeñas y medianas empresas

En el Libro Blanco se constata un aumento de la mortalidad de las PIMEs. Este hecho es especialmente preocupante por cuanto las PIMEs proporcionan el mayor volumen de empleo en la Comunidad (70'2\%). Las PIMEs tienen, además, un gran potencial de creación de empleo, juegan un papel esencial en la dotación del primer empleo y tienen especial capacidad para absorber a los trabajadores más desfavorecidos (jóvenes, mujeres, trabajadores no cualificados) $)^{42}$.

Las propuestas estratégicas del Libro Blanco

En el Libro Blanco se proponen una serie de medidas estratégicas para hacer frente a los problemas que allí se analizan. Así, frente a la globalización de la economía, el Capítulo VI del libro pretende configurar a la Comunidad como «un partenaire abierto y solidario». Pero la «filosofía» de esta «solidaridad» queda puesta de manifiesto en la siguiente cita: «no es demasiado pronto para orientar el debate hacia las estrategias que mejor permitan a la Comunidad Europea obtener ventajas del mercado mundial de la post-ronda [Uruguay] (beneficios, cuotas de mercado, nuevas inversiones y relaciones de negocios) $\rangle^{43}$. Esa solidaridad consiste, pues, en obtener el mayor beneficio posible.

\footnotetext{
${ }^{41}$ Livre Blanc, págs. 64-65.

${ }^{42}$ Livre Blanc, pág. 73.

${ }^{43}$ Livre Blanc, pág. 113.
} 
«La apertura de los mercados a la libre competencia es uno de los objetivos del Tratado de la Unión Europea. La Unión tiene un gran interés en promover la apertura de los mercados tanto dentro como fuera de la Comunidad». Esta estrategia de eliminar las barreras al «buen funcionamiento» de los mercados parece entrar en contradicción con las propuestas de defensa de las pequeñas y medianas empresas. En particular, porque en el informe se señala que los «puntos fuertes» de las PIMEs residen precisamente en su capacidad de instalarse en ámbitos menos susceptibles a la competencia internacional, en «nichos de mercados». O bien se protegen estos «nichos» para que no aumente la «mortalidad» de las PIMEs, o bien se deja que el capitalismo funcione «a su aire», con lo que las PIMEs estarán cada vez más en peligro de extinción.

En cuanto al problema del empleo las propuestas del Libro Blanco siguen la filosofía del trabajar menos para trabajar todos. En ese sentido, se señalan los éxitos obtenidos en los Países Bajos y en Dinamarca como consecuencia de la reducción de la jornada semanal (33 horas en los Países Bajos y 35 horas en Dinamarca). El volumen total de horas trabajadas ha aumentado un $2 \%$ en Dinamarca, pero el número total de personas empleadas ha aumentado un $8 \%$. Ha tenido lugar paralelamente un incremento notable de la proporción de personas que trabajan a tiempo parcial. En los Países Bajos, el aumento del empleo en un $30 \%$ parece atribuible en más de la mitad a la reducción de la jornada de trabajo ${ }^{46}$.

No obstante, la propuesta de trabajar menos para trabajar todos tal como aparece desarrollada en el informe no cuestiona la libertad de inversión de las empresas, que es uno de los elementos de la libertad de empresa que tiene que quedar necesariamente afectado para poder asegurar que la reducción de jornada se traduzca en creación de nuevos empleos $^{47}$.

En el informe no se considera una buena táctica la de reducir la protección social en Europa, sino que se defiende una política de

${ }^{44}$ Livre Blanc, pág. 73.

${ }^{45}$ Livre Blanc, pág. 131

${ }^{46}$ Livre Blanc, pág. 110.

${ }^{47} \mathrm{En}$ el marco de la polémica que suscitó en su día la propuesta de Lafontaine, Von Oertzen señaló que la capacidad de obligar a las empresas a contratar nuevos trabajadores (a cambio de las reducciones de jornada con reducción de salario) implica un ataque central contra el núcleo de la libertad de empresa: la política de personal, la política de reparto de beneficios y la política de inversiones deberían poder ser sometidas a control para poder hacer efectiva la transformación de la solidaridad en puestos de trabajo (Von Oertzen: «Antikapitalistische Haltung kann das Programm nicht ersetzen», en La Fontaine, O. y otros, Das Lied vom Teilen, Hoffmann und Campe, 1989, págs. 158-76, págs. 169-70. 
mantener esa protección social y, a la vez, no ignorarla en otras partes, intentando fomentar la legislación social en los países competidores ${ }^{48}$. No obstante esta propuesta parece estar en contradicción con la política seguida hasta ahora por la Comunidad en materia de cohesión social.

Por lo que se refiere al aspecto organizativo, el informe propone que se dote de mayores medios y competencias a la Comisión para que la comunidad pueda adoptar decisiones más ágilmente. Esto comportaría un aumento del déficit democrático, al dar aún más poder al aparato administrativo ${ }^{49}$.

\section{La necesidad de replantear los objetivos de Europa}

Sin negar el interés que tienen, al menos aisladamente, algunas de las propuestas del Libro Blanco, no parece, sin embargo, que la solución del problema del paro, de las disparidades reales entre la economía de los diferentes países, de la solidaridad con el resto del mundo puedan alcanzarse sin un replanteamiento general de los objetivos reales de la Unión Europea.

El futuro de la construcción europea debería basarse en una filosofía completamente distinta a la de dejar que el capitalismo funcione «a su aire»-que es la que predomina en el Libro Blanco- para orientarse hacia la profundización de la cohesión social y la creación de mecanismos de intervención pública y redistributivos a escala europea. Sólo así se podría configurar un bien común europeo. Y sólo así sería posible una ciudadanía europea que constituyera un sujeto político capaz de enfrentarse a los problemas en su actual dimensión.

${ }^{48}$ Livre Blanc, pág. 115.

${ }^{49}$ Livre Blanc, pág. 113. 